\title{
EFEITO DO PISOTEIO BOVINO EM ALGUMAS PROPRIEDADES FÍSICAS DO SOLO DE VÁRZEA ${ }^{1}$
}

\author{
EFFECT OF CATTLE TRAMPLING ON LOWLAND SOIL PHYSICAL PROPERTIES
}

\author{
Vandro Rogério Vzzotto ${ }^{2}$ Enio Marchezan ${ }^{3}$ Tommi Segabinazzi ${ }^{4}$
}

\section{RESUMO}

\begin{abstract}
O objetivo do trabalho foi avaliar a influência do pisoteio de animais bovinos sobre propriedades físicas de um solo de várzea cultivado com consórcio de espécies forrageiras de inverno. Utilizaram-se azevém (Lolium multiflorum) + trevo branco (Trifolium repens) + cornichão (Lotus corniculatus), semeadas dia 05 de abril de 1997, em solo classificado como Planossolo, cuja área foi sistematizada em desnível de $0,06 \mathrm{~mm}^{-1}$. $O$ delineamento experimental foi o de blocos ao acaso com três tratamentos e seis repetições. Os tratamentos constaram das épocas de avaliação das características físicas do solo; $T 1=$ antes da entrada dos animais, T2 = após a saída dos animais e T3 = seis meses após o término do pastejo. Cada piquete (Repetição) de 0,5ha constituiu-se numa parcela, adotando-se pastejo contínuo com terneiros de 8-10 meses de idade e carga inicial média de $480 \mathrm{~kg} \mathrm{ha}^{-1}$ de peso vivo, sendo que o resíduo de massa de forragem foi mantido ao redor de $1000 \mathrm{~kg} / \mathrm{ha}^{-1}$. O pisoteio animal ocasiona aumento da densidade do solo e redução da porosidade total. Nos primeiros cinco cm da superfície do solo, ocorre aumento da densidade do solo. Seis meses sem pisoteio não foram suficientes para que as raízes das plantas realizassem a descompactação do solo.
\end{abstract}

Palavras-chave: compactação, porosidade do solo, densidade do solo, manejo do solo de várzea.

\section{SUMMARY}

The objetive of the work was to evaluate effects of bovine stepping on the physical proprieties of a lowland soil where a mixture of winter pastures were grown. The plant species were italian ryegrass (Lolium multiflorum), white clover (Trifolium repens) and birdsfoot trefoil (Lotus corniculatus). The soil is classified as an albaqualf, previously leveled with a $0,06 \%$ gradient. The experimental design was a randomized block in which each plot measured 0,5ha forming six experimental units under continuous grazzing. The soil treatments were the occasions in which the samplimg were taken; $T 1=$ just before entrance of the animals, T2 = immediately after their exit and T3 = six months later. The animals were 8-10 months old calves with an initial load of $480 \mathrm{~kg} / \mathrm{ha}^{-1}$ of live load and the residual pasture mass was about $1000 \mathrm{~kg} / \mathrm{ha}^{-1}$. Animal stepping caused an increase on soil density and a reduction in total porosity. An increase on soil density occurred at the first $5 \mathrm{~cm}$ soil depth. Six months with no stepping were not sufficient for plant roots to decrease soil compactation.

Key words: soil compaction, soil density, soil porosity, lowland management.

\section{INTRODUÇÃO}

No Rio Grande do Sul, há aproximadamente 5.300,000 hectares de várzea (KLAMT et al., 1985), sendo que em torno de 900.000 hectares são cultivados anualmente com arroz, uma pequena fração com milho e soja e o restante da área é utilizada para a produção animal, especialmente bovinos.

O uso sustentável das áreas de várzea depende de um planejamento adequado de sua utilização e, nesse sentido, a integração lavoura/pecuária, com o uso de pastagens cultivadas, têm um papel importante no aproveitamento intensivo dessas áreas no período de inverno. Faz-se necessário, no entanto, conhecer os efeitos do pisoteio animal sobre as características físicas do solo, pois, de acordo com VIEIRA (1985), o aumento da densidade e da microporosidade do solo e a redução da porosidade

\footnotetext{
${ }^{1}$ Parte da Dissertação em Agronomia do primeiro autor; trabalho realizado com auxílio financeiro da FAPERGS.

${ }^{2}$ Engenheiro Agrônomo, MSc., Autônomo.

${ }^{3}$ Engenheiro Agrônomo, Professor Doutor, Departamento de Fitotecnia (DF), Centro de Ciências Rurais (CCR), Universidade Federal de Santa Maria (UFSM), Pesquisador do CNPq. 97105-900, Santa Maria, RS. E-mail: emarch@ccr.ufsm.br. Autor para correspondência.

${ }^{4}$ Acadêmico de Agronomia da UFSM, bolsista da FAPERGS. 
total e da macroporosidade promovem alterações nas relações de ar, água e temperatura do solo, afetando negativamente a germinação, emergência, crescimento e produção das plantas.

O crescimento e desenvolvimento das plantas dependem das condições químicas e físicas do solo, além da drenagem da área, especialmente, quando se tratar de solos de várzea. Estes solos apresentam, em sua maioria, relevo plano a levemente ondulado, existência de um horizonte B, impermeável, e presença do lençol freático próximo à superfície (KLAMT, 1986).

A compactação afeta inicialmente os macroporos estabelecendo inadequada difusividade dos gases do solo. SOUSA et al. (1994) concluíram que cultivos não adaptados ao excesso de água no solo exigem um mínimo de $10 \%$ de espaço aéreo para o desenvolvimento satisfatório. Nesse sentido, PEDROTTI $\boldsymbol{e}$ t al. (1995) observaram em um experimento conduzido em casa de vegetação, que o desenvolvimento da soja, do milho, do arroz irrigado e de sequeiro foi afetado negativamente com o aumento da densidade do solo de 1,3 para 1,6 e $1,9 \mathrm{~g} / \mathrm{cm}^{-2}$. As raízes das plantas apresentaram maior ramificação nas densidades mais elevadas, até aos 21 dias após a emergência. SILVA (1986) relata que em poucos minutos o crescimento radicular pode ser interrompido pela falta de oxigênio devido à baixa macroporosidade e ao excesso de água, ou por ambas, porém, as raízes voltam a crescer logo após o suprimento de oxigênio ser reestabelecido.

Relatos de literatura como os de MORAES \& LUSTOSA (1997), evidenciam o efeito do pisoteio animal na compatação do solo, cuja magnitude depende da categoria e da carga animal, entre outros fatores. No entanto, BASSANI (1996), utilizando carga animal média de $775 \mathrm{~kg} / \mathrm{ha}^{-1}$ de peso vivo e resíduo mínimo de $1500 \mathrm{~kg} / \mathrm{ha}^{-1}$ de matéria seca composta de aveia (Avena strigosa schred) + azevém (Lolium multiflorum), não encontrou compactação do solo, tendo atribuido à massa de forragem o efeito atenuante do choque da pata bovina no solo.

Para solos de várzea, no entanto, não se dispõe de informações do efeito do pisoteio dos animais sobre propriedades físicas do solo, sendo importante essa caracterização para orientar sobre procedimentos de manejo a serem adotados após a utilização da área com a pecuária.

Assim, este trabalho teve por objetivo avaliar modificações em propriedades físicas do solo de várzea em função do pisoteio de animais bovinos e do período após o pastejo sem a presença de animais.

\section{MATERIAL E MÉTODOS}

O experimento foi instalado em área de várzea na estação hibernal de 1997, localizada no Campus da Universidade Federal de Santa Maria, Rio Grande do Sul (RS), em solo classificado como Planossolo (BRASIL, 1973).

Antes da instalação do experimento, a área foi sistematizada, adotando-se $0,06 \mathrm{~m} \cdot \mathrm{m}^{-1} \mathrm{de}$ desnível, aproximadamente. No processo de regularização da superfície do terreno, foram realizados cortes máximos de $0,3 \mathrm{~m}$ no perfil do solo. Após o nivelamento, em cada talhão, foi realizado um dreno superficial central, no sentido da declividade, com $0,12 \mathrm{~m}$ de largura e $0,20 \mathrm{~m}$ de profundidade.

A semeadura, no sistema convencional, foi realizada no dia 5 de abril de 1997, em solo com teor de umidade adequado à operação de semeadura e à emergência das plantas, utilizando-se semeadora com espaçamento entre linhas de $0,17 \mathrm{~m}$, aplicandose após a semeadura um rolo leve do tipo "Brillion", que possuía diâmetro de cerca de $0,20 \mathrm{~m}$, largura de $3,0 \mathrm{~m}$ e peso estimado de $300 \mathrm{~kg}$, com o objetivo de melhorar o contato da semente com o solo e com isso facilitar a emergência das plantas.

A quantidade de sementes utilizada correspondeu a $40 \mathrm{~kg} / \mathrm{ha}^{-1}$ de azevém (Lolium multiflorum Lam), 7,5kg/ha-1 de cornichão (Lotus corniculatus $c v$. São Gabriel) e $2 \mathrm{~kg} / \mathrm{ha}^{-1}$ de trevo branco (Trifolium repens $c v$. Zapican).

A análise do solo, média da área experimental, revelou $24,5 \%$ de argila, $\mathrm{pH} 4,9, \mathrm{P}=$ $5,2 \mathrm{mg} / \ell, \mathrm{K}=59 \mathrm{mg} / \ell, \mathrm{M} . \mathrm{O}=1,45 \% \mathrm{~m} / \mathrm{V}, \mathrm{Al}=$ $0,94 \mathrm{cmol}_{\mathrm{c}} / \ell, \mathrm{Ca}=3,8 \mathrm{cmol}_{\mathrm{c}} / \ell$ e $\mathrm{Mg}=2,0 \mathrm{cmol}_{\mathrm{c}} / \ell . \mathrm{A}$ adubação foi realizada no momento da semeadura de acordo com a recomendação para o consórcio das espécies utilizadas. Utilizou-se adubação de cobertura com nitrogênio, em três épocas, com $20 \mathrm{~kg} / \mathrm{ha}^{-1} \mathrm{de}$ nitrogênio na forma de uréia, em cada época.

Os animais utilizados pertenciam à raça Charolês, com idade média de 8 a 10 meses.

Utilizou-se sistema de pastejo contínuo, com lotação fixa (GARDNER, 1986), correspondendo a 4 animais $\mathrm{ha}^{-1}$. A carga média foi de $738 \mathrm{~kg} / \mathrm{ha}^{-1}$ de peso vivo e o início do pastejo em cada tratamento ocorreu no momento em que a massa de forragem alcançou $1.000 \mathrm{~kg} / \mathrm{ha}^{-1}$ de matéria seca, sendo que o período de pastejo médio foi de 116 dias.

O delineamento experimental foi o de blocos ao acaso com três tratamentos e seis repetições. Os tratamentos constaram das épocas de avaliação das características físicas do solo $\mathrm{T} 1$ = antes da entrada dos animais, T2 = após a saída dos animais e T3 = seis meses após o término do pastejo. As unidades experimentais foram seis piquetes, contendo 2 animais por piquete com área de 0,5ha cada um. 
Para avaliar a profundidade de compactação, utilizou-se um cilindro com $25 \mathrm{~cm}$ de profundidade e $5,6 \mathrm{~cm}$ de diâmetro, extraindo secções de $5 \mathrm{~cm}$ do monolito, onde se determinou a densidade do solo como parâmetro de comparação entre elas. Foram realizadas duas amostragens por parcela nas três épocas descritas anteriormente. Com o objetivo de uniformizar a pressão para penetração do cilindro no solo, utilizou-se um macaco hidráulico situado entre o cilindro amostrador e o eixo dianteiro de um trator, evitando-se a influência da carga da máquina na característica física avaliada.

A densidade do solo, porosidade, macro e microporosidade foram avaliadas, utilizando-se o cilindro de Uhland, através da coleta de 6 amostras por piquete à profundidade de $0-10 \mathrm{~cm}$, nas três épocas citadas anteriormente. Todas as características físicas do solo avaliadas no experimento foram realizadas segundo metodologia descrita em (EMBRAPA-CNPS, 1997).

No período de pastejo, foram coletadas, semanalmente, quatro amostras da superfície do solo por piquete, para avaliação da umidade. A capacidade de campo foi determinada pelo método volumétrico, segundo metodologia proposta por (EMBRAPA-CNPS, 1997).

Os dados foram submetidos à análise de variância, e as médias dos tratamentos foram comparadas entre si pelo teste de Tukey em nível de $5 \%$ de probabilidade.

\section{RESULTADOS E DISCUSSÃO}

$\mathrm{Na}$ tabela 1, observa-se a variação da densidade do solo a cada $5 \mathrm{~cm}$ de profundidade no perfil, quando foi utilizado o cilindro de $25 \mathrm{~cm}$ de

Tabela 1 - Densidade do solo de várzea, em diferentes épocas: antes do início do pastejo(época 1), no término o pastejo(época 2) e seis meses após o término do pastejo(época 3), em diferentes profundidades de amostragem. Santa Maria, RS. 1999.

\begin{tabular}{|c|c|c|c|c|c|c|}
\hline \multirow[b]{2}{*}{ Épocas } & \multicolumn{6}{|c|}{ Profundidades $(\mathrm{cm})$} \\
\hline & $0-5$ & $5-10$ & $10-15$ & $15-20$ & $20-25$ & Média \\
\hline Época 1 & $1,20 b^{*}$ & $1,32^{\mathrm{ns}}$ & $1,30^{\mathrm{ns}}$ & $1,30^{\mathrm{ns}}$ & $1,29^{\mathrm{ns}}$ & 1,27 \\
\hline Época 2 & $1,30 \mathrm{a}$ & 1,32 & 1,30 & 1,30 & 1,29 & 1,30 \\
\hline Época 3 & $1,24 \mathrm{ab}$ & 1,30 & 1,29 & 1,29 & 1,27 & 1,28 \\
\hline Média & 1,25 & 1,30 & 1,30 & 1,29 & 1,28 & \\
\hline $\mathrm{CV}(\%)$ & & & & & & 3,68 \\
\hline
\end{tabular}

\footnotetext{
* Médias na coluna, seguidas da mesma letra, não diferem entre si pelo teste de Tukey em nível de $5 \%$ de probabilidade.
}

ns Teste F não significativo em nível de $5 \%$ de probabilidade. comprimento. Comparando as coletas realizadas antes do início do pastejo (época 1) e após o término do pastejo (época 2), constata-se que houve compactação somente na profundidade de $0-5 \mathrm{~cm}$. Esses resultados estão de acordo com os obtidos por TREIN et al. (1991), que observaram o efeito do pisoteio de animais bovinos num período curto (40 horas), com lotação muito elevada (200 cabeças/ha), ocasionando compactação nos $7,5 \mathrm{~cm}$ superficiais do solo. Resultados semelhantes também foram obtidos por CORREA \& REICHARDT (1995), avaliando a influência do tempo de 4, 6 e 10 anos de pastejo em características físicas de um latossolo amarelo, tendo concluindo que houve aumento da resistência à penetração com o passar dos anos de pastejo, na camada de $0-10 \mathrm{~cm}$ de solo. Em outro trabalho, conduzido com o objetivo de avaliar intensidades de pastejo, SCHNEIDER et al. (1981), observaram que, em período de dois anos com pastejo direto de bovinos no sistema contínuo, as modificações foram mais acentuadas nos períodos iniciais e se manifestaram mais intensamente na camada superficial.

$\mathrm{Na}$ tabela 2, encontram-se as características físicas do solo avaliadas pelo cilindro de Uhland, nos primeiros 10 centímetros do solo. Comparando os resultados obtidos antes do pastejo (época 1) e depois do pastejo (época 2), verifica-se que o pisoteio animal exerceu influência sobre algumas propriedades físicas do solo, ocasionando aumento na densidade e redução da porosidade total e da macroporosidade, dado semelhante ao encontrado por MARCHEZAN et al. (1998), trabalhando no mesmo solo.

Ainda na tabela 2, constata-se que a microporosidade não sofreu influência do pisoteio animal, pois não houve diferença signicativa neste fator entre o início e o final do pastejo. Já a macroporosidade foi reduzida, quando comparada com os valores iniciais. Segundo SOUSA et al. (1994), a percentagem de macroporos não deveria ser inferior a $10 \%$ para permitir uma adequada aeração do solo, proporcionando bom desenvolvimento de plantas. A baixa percentagem de macroporos caracteriza que pode ter havido interferência no desenvolvimento das forrageiras, limitando a produção de massa seca total. A avaliação de macroporosidade realizada por MARCHEZAN et $\boldsymbol{a l}$. (1998) também em solo de várzea, apresentou, antes do pastejo, valor próximo a $10 \%$ e, após o término do pastejo, redução dos macroporos e aumento da microporosidade.

A comparação das características avaliadas na época 3 (seis meses após o término do pastejo) com aquelas verificadas na época 2 (término do pastejo), visualizada através da tabela 2 , revela que o período de tempo de seis meses após a retirada dos 
Tabela 2 - Propriedades físicas do solo de várzea, coletadas com cilindro de Uhland, antes do início do pastejo(época 1), no término do pastejo(época 2) e seis meses após o término do pastejo(época 3), na profundidade de 0-10 cm. Santa Maria, RS. 1999.

Densidade Porosidade total Microporosidade Macroporosidade

\begin{tabular}{lllll} 
& & & & \\
\cline { 3 - 5 } Épocas & $\left(\mathrm{g} / \mathrm{cm}^{3}\right)$ & - & & \\
& & & & \\
Época 1 & $1,38 \mathrm{~b}^{*}$ & $45,34 \mathrm{a}$ & $37,72 \mathrm{a}$ & $7,62 \mathrm{a}$ \\
Época 2 & $1,48 \mathrm{a}$ & $42,50 \mathrm{~b}$ & $36,65 \mathrm{ab}$ & $6,14 \mathrm{~b}$ \\
Época 3 & $1,45 \mathrm{a}$ & $42,76 \mathrm{~b}$ & $35,73 \mathrm{~b}$ & $7,03 \mathrm{ab}$ \\
& & & & \\
$\mathrm{CV}(\%)$ & 3,09 & 4,21 & 3,53 & 11,75 \\
\hline
\end{tabular}

* Médias na coluna, seguidas da mesma letra, não diferem entre si pelo teste de Tukey em nível de $5 \%$ de probabilidade.

animais não foi suficiente para que as raízes das plantas, que se estabeleceram na área, exercessem trabalho de descompactação do solo, porém proporcionou aumento da macroporosidade, possibilitando chegar a níveis semelhantes àqueles verificados antes do início do pastejo. No entanto, como o solo em estudo apresenta densidade natural elevada (KLAMT, 1986), a redução, ainda que pequena da densidade do solo neste período, e o aumento da macroporosidade indicam melhoria nas condições físicas do mesmo, o que pode contribuir para o cultivo de espécies de sequeiro. Entretanto, são necessárias maiores informações, com relação ao desenvolvimento de espécies nesses níveis de melhoria, para realizar um manejo adequado de áreas de várzea, com cultivos subseqüentes à utilização da área com pecuária. Em trabalho conduzido com o objetivo de recuperação de solos degradados, MORAES \& LUSTOSA (1997) encontraram efeito de descompactação do solo pela ação biológica das raízes da pastagem cultivada e pela atividade da mesofauna do solo. De acordo com os autores, isso ocorre quando a pastagem é submetida a condições de manejo que propiciem o acúmulo de fitomassa na parte aérea e no sistema radicular das plantas.

A permanência dos bovinos na área durante todos os dias do experimento, numa época do ano em que é freqüente o excesso de água por períodos prolongados, inclusive com formação de lâmina de água sobre a superfície do solo, pode ter contribuído para ocorrer a compactação do solo. Na figura 1, está expresso o comportamento da umidade do solo durante o período de pastejo. Observa-se que o mesmo permaneceu a maior parte do período experimental com conteúdo de água acima da capacidade de campo. CORREA \& REICHARDT (1995) citam que solos argilosos, com umidade elevada, tornam-se plásticos e, com a compressão causada por equipamentos ou por pisoteio dos animais ocorre um aumento da densidade global. Por outro lado, PROCTOR (1993), observou que a densidade do solo, inicialmente, aumenta com a elevação do grau de umidade do solo pra, em seguida, decrescer; já Kiehl (1971), apud BALLESTERO \& ZILLER (1997), obteve valores decrescentes de densidade do solo com aumento da umidade do mesmo.

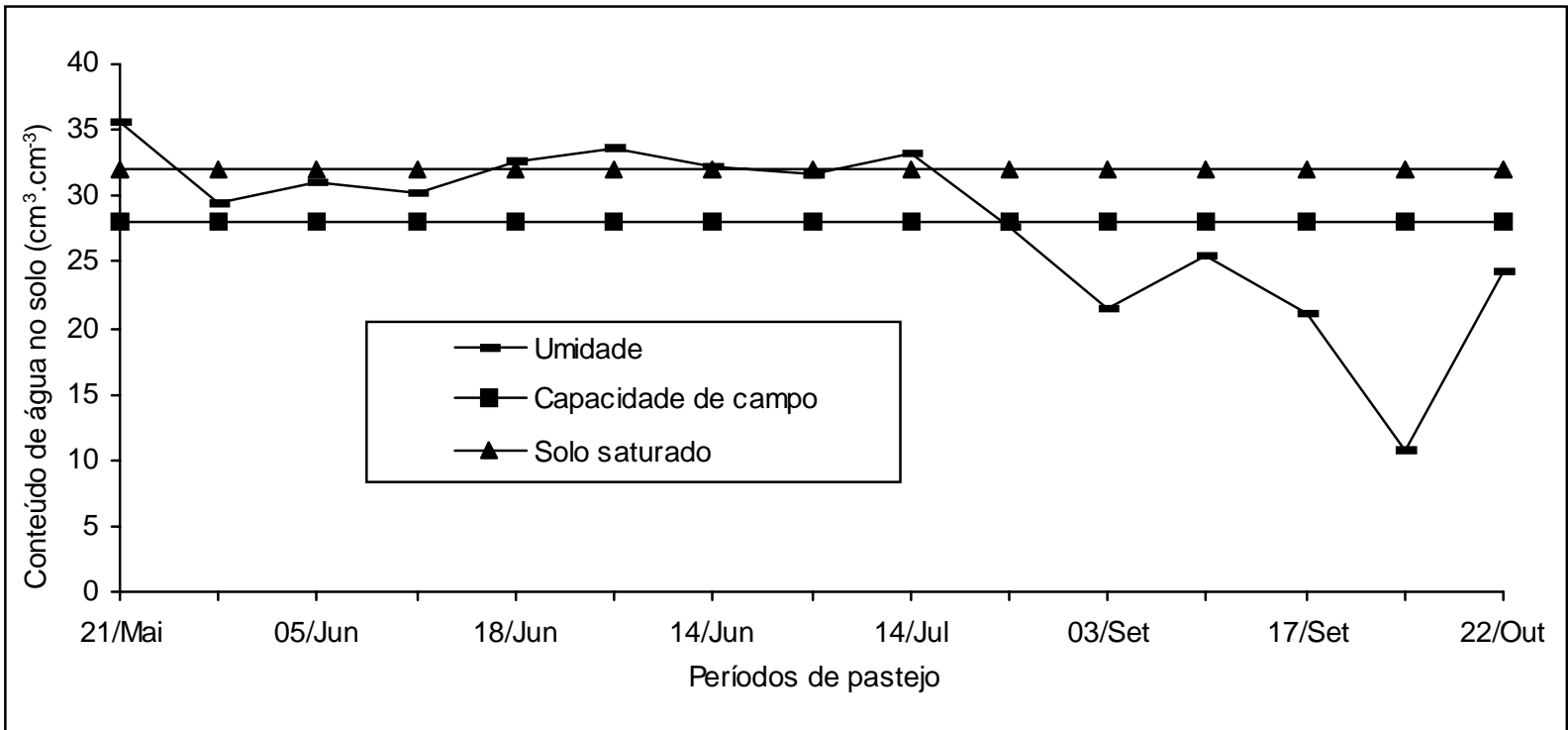

Figura 1 - Umidade volumétrica do solo coletado durante a fase de desenvolvimento da pastagem cultivada. Santa Maria, RS. 1999. 


\section{CONCLUSÕES}

O pisoteio animal ocasiona redução da porosidade total e aumento da densidade do solo.

$\mathrm{O}$ aumento da densidade do solo ocorre nos primeiros cinco centímetros.

Um período de seis meses após o término do pastejo não é suficiente para que as raízes das plantas realizem o trabalho de descompactação do solo, porém é suficiente para que a macroporosidade atinja níveis semelhantes àqueles constatados antes do início do pisoteio.

\section{REFERÊNCIAS BIBLIOGRÁFICAS}

BALLESTERO, S.D., ZILLER, Z. Relação entre densidade e umidade em terra compactada e agregada. In: CONGRESSO BRASILEIRO DE CIÊCIA DO SOLO, 1997, Rio de Janeiro, RJ. Anais ... Rio de Janeiro : Sociedade Brasileira de Ciência do Solo, 1997. 494p. p.19

BASSANI, H.J. Propriedades físicas do solo e produtividade de milho induzida pelo plantio direto e convencional em área pastejada e não pastejada. Santa Maria, 1996. 90p. Dissertação (Mestrado em Agronomia) - Curso de Pósgraduação em Agronomia, Universidade Federal de Santa Maria, 1996.

BRASIL - Ministério da Agricultura. Levantamento de reconhecimento dos solos do Rio Grande do Sul. Recife, 1973. 431p. (Boletim Técnico n.30).

CORREA, J.C., REICHARDT, K. Efeito do tempo de uso das pastagens sobre as propriedades de um latossolo amarelo da Amazônia Central. Pesquisa Agropecúaria Brasileira, Brasília, v.30, p.107-114. 1995.

EMBRAPA. Manual de métodos e análise do solo. 2 ed. Rio de Janeiro : CNPS, 1997. 212p.

GARDNER, A.L. Técnicas de pesquisa em pastagem e aplicabilidade de resultados em sistemas de produção. Brasília. EMBRAPA - CNPGL, 1986. 197p.

KLAMT, E., KÄMPF, N., SCHNEIDER, P. Solos de várzea no estado do Rio Grande do Sul. Porto Alegre : IRGA, 1985. 42p. (Boletim Técnico n. 04).

KLAMT, E. Solos de várzea do Rio Grande do Sul: característica, distribuição e limitações ao uso. In: SIMPÓSIO SOBRE ALTERNATIVA AO SISTEMA TRADICIONAL DE UTILIZAÇÃO DE VÁRZEAS DO RIO GRANDE DO SUL,
1984, Porto Alegre, RS. Anais ... Brasília : PROVÁRZEAS/PROFIR, 1986. v.1. 319p. p.111-118.

MARCHEZAN, E., VIZZOTTO, V.R., ZIMMERMAN, F.L. Produção de forrageiras de inverno em diferentes espaçamentos entre drenos superficiais sob pastejo animal em várzea. Ciência Rural, Santa Maria, v.28, n.3, p.393-397, 1998.

MORAES, A. de, LUSTOSA, S.B.C. Efeito do animal sobre as características do solo e a produção da pastagem. In: SIMPÓSIO SOBRE AVALIAÇÃO DE PASTAGENS COM ANIMAIS, 1997, Maringá, PR. Anais... Maringá : Universidade Estadual de Maringá, 1997. 149 p. p.129-149.

PEDROTTI, A., VAHL, L.C., PAULETTO, E.A. Desenvolvimento radicular em arroz, soja e milho, em função da compactação de um planossolo. In: CONGRESSO BRASILEIRO DE FISIOLOGIA VEGETAL, 1995, Lavras, MG. Resumos... Lavras : Sociedade Brasileira de Fisiologia Vegetal- Universidade Federal de Lavras, 1995. 123p. p.22.

PROCTOR, R.R. Fundamental principles of soil compaction, Engineering News - Record, v.111, n. 9, 10, 12, 13, 157p, 1933.

SCHNEIDER, P., SCOPEL, I., KLAMT, E. Efeito da pastagem cultivada, submetida a diferentes intensidades de pastejo, em propriedades físicas de um solo laterítico hidromórfico. In: ENCONTRO NACIONAL DE PESQUISA SOBRE CONSERVAÇÃO DO SOLO, 1981, Recife, PE. Anais... Recife : Sociedade Brasileira Ciência do Solo, 1981. v.3. 532p. p.343-350

SILVA, A.R. Tolerância ao encharcamento. In: SIMPÓSIO SOBRE ALTERNATIVA AO SISTEMA TRADICIONAL DE UTILIZAÇÃO DE VÁRZEAS DO RIO GRANDE DO SUL, 1986, Porto Alegre, RS. Anais... Brasília : PROVÁRZEAS/PROFIR, 1986. v.1. 319p. p.166-181.

SOUSA, R.O, PAUlETTO, E.A, GOMES, A.S. Sistemas de cultivo de arroz irrigado no Rio Grande do Sul. In CONFERÊNCIA INTERNACIONAL DE ARROZ PARA A AMERICA LATINA E PARA O CARIBE, e REUNIÃO NACIONAL DE PESQUISA DE ARROZ, 1994, Goiânia, GO. Anais... Goiânia : EMBRAPA/CNPAF, 1994. v.1 296p. p.151-168.

TREIN, C.R, COGO, N.P, LEVIEN, R. Métodos de preparo do solo na cultura do milho e ressemeadura do trevo, na rotação aveia+trevo/milho, após pastejo intensivo. Revista Brasileira de Ciência do Solo, Campinas, v.15, p.105-111, 1991.

VIEIRA, M.J. Comportamento físico do solo em plantio direto. In: FANCELLI, A.L., TORRADO, P.V., MACHADO, J. Atualização em plantio direto. Campinas : Fundação Cargill, 1985. p.163-179. 